\title{
Factors associated with the utilization of postnatal care services among Malawian women
}

\section{Jessie Jane Khaki ${ }^{1}$, Lonjezo Sithole ${ }^{2}$}

1. University of Malawi, College of Medicine, Department of Public Health

2. The University of Edinburgh, School of Economics, United Kingdom
Date Received: 30-Apr-2018

Revision Received: 08-Oct-2018

Date Accepted: 10-Oct-2018

Correspondence:

jkhaki@medcol.mw

https://dx.doi.org/10.4314/mmj.v31i1.2

\begin{abstract}
Introduction
The World Health Organization (WHO) recommends that every woman be checked after the delivery of a child. However, only $42 \%$ of Malawian women are checked by a skilled health worker within 48 hours after delivery. This study aimed at identifying factors associated with postnatal care (PNC) utilization among Malawian women by using nationally representative data.

Methods

Secondary data from the 2015-2016 Malawi Demographic and Health Survey (MDHS) was used for the study. A logistic regression model was used to find the adjusted odds of utilizing PNC services among the women. All the analyses controlled for the survey clusters and weighting. All the analyses were conducted in STATA version 14 at a significance level of 5\%.

Results

Out of the 6,693 women who had a live birth 24 months prior to the 2015-2016 MDHS, only 48.4\% were checked by a skilled health worker within 42 days after delivery. Uptake of PNC was significantly associated with older age, being employed, living in an urban area, delivery through caesarean section, a timely first antenatal care (ANC) visit, uptake of recommended number of ANC visits, and receiving the adequate number of tetanus injections.

Conclusion

Interventions to increase utilization of PNC services should be tailored to appropriate populations. Particularly, special focus has to be made towards younger women, the women who reside in the rural areas, who are not employed, and who are generally not well to do. Behavioural change interventions must also target women with low perceived risk after delivery. Information should also be consistently provided by health workers in communities and health facilities to women on perinatal care in order to change the women's risk perception on all levels of pregnancy care and to encourage utilization of relevant health services.

Key Words: Postnatal care, Women, Malawi, Demographic and Health Survey.
\end{abstract}

\section{Introduction}

The World Health Organization (WHO) defines a postnatal period as the six weeks after the delivery of a child ${ }^{1,2}$. This period is deemed critical for both the mother and the child because most maternal and neonatal deaths occur within the period. It is reported that close to half of all maternal deaths occur mostly during the first 24 hours after birth, and in the first week after birth ${ }^{3}$.

Globally, 216 women per 100,000 live births die every year due to pregnancy related complications ${ }^{4}$. Target 3.1 in the Sustainable Development Goals ${ }^{5}$ aims at reducing the global maternal mortality to 70 women per 100,000 live births by 2030. There has, generally, been a substantial decrease in the maternal mortality rate. The rates have decreased from 675 maternal deaths per 100,000 live births in 2010 to 439 maternal deaths per 100,000 live births in the 7 years prior to the 2015-2016 Malawi Demographic and Health (MDHS) survey ${ }^{6}$, progress in increasing utilization of Post Natal Care (PNC) services has stalled. The 2010 MDHS reported that only $43 \%$ of all the women in the two years prior to the survey had accessed PNC services within 48 hours of birth. This decreased to $42 \%$ in the 2015-2016 MDHS.
To help countries alleviate the situation, the WHO provided recommendations on how a mother who has just delivered should be treated. One such recommendation is that a mother who has delivered should be checked by a health worker (HW) within 24 hours of delivery. Postnatal care has also been highly recommended by the 2016-2030 Global Strategy for Women's, Children's and Adolescents health'7. The Malawi Sexual and Reproductive Health and Rights (SRHR) Policy also recommends strengthening community awareness on the importance of male involvement in all maternal and neonatal health care to increase utilization of the services by women ${ }^{8}$.

A number of studies have looked at some of the factors that are associated with the uptake of postnatal care services in Malawi. However, most of these studies concentrated only on few facilities within the country ${ }^{9,10}$, while others were simply qualitative ${ }^{11,13}$. These studies showed that PNC utilization is significantly associated with the educational level ${ }^{9,10}$ and employment status of the woman ${ }^{10}$. This study, therefore, aimed at investigating quantitatively the factors that are associated with the uptake of PNC services in order to inform policy and decision making at a national level. 


\section{Methods \\ Data Collection}

The study used secondary data from the 2015-2016 Malawi Demographic and Health Survey (MDHS) which was collected between October 2015 and February 2017. The DHS is a nationally representative survey that is conducted every five years in Malawi to collect information on population, maternal and child health and nutrition at national and subnational levels ${ }^{6}$.

The 2015-2016 DHS used a two-stage sampling method. Firstly, all the 28 administrative districts in Malawi were stratified into urban or rural areas. Then standard enumeration areas (SEAs) were selected randomly and independently within each stratum. Specifically, the study used the women's record which contains information on women aged 15 to 49. Out of the 24,562 women interviewed for the survey, a total of 6,693 women had a live birth in the 24 months prior to the survey.

\section{Statistical analysis}

Frequency distributions were used to describe the population. Unadjusted and adjusted multilevel logistic regression models were used to determine factors that are associated with the use or non-use of PNC services. Both the univariate and multivariate analyses were adjusted for the complex design of the DHS. The individual women's sampling weights were used to adjust for disproportionate sampling and nonresponse in the data. All analyses were carried out in Stata version 14 . The results were interpreted at a significance level of $5 \%$.

\section{Ethical consideration}

Permission to use the 2015-2016 MDHS data was obtained from the DHS program. There were no other ethical considerations on the part of the researchers, as the dataset is completely anonymized and all other pertinent ethical issues were handled by the DHS program before and during the survey.

\section{Outcome and explanatory variables}

In the DHS, respondents are asked whether or not they had a live birth in the 24 months prior to the survey. If they did, they are further requested to divulge whether or not their health was checked after discharge or delivery at home, who checked the respondent, and how long after discharge or delivery at home it took for them to receive the first check. These checks include prevention, examination and management of postpartum hemorrhage, sepsis and eclampsia ${ }^{7}$.

The main outcome of interest in the study was whether or not a woman was checked by a skilled health worker (HW) during the first 42 days after delivery. This is consistent with the WHO's definition of postnatal period, which spans 42 days after delivery. A skilled HW included doctors, clinical officers, medical assistants, nurses, midwives, patient attendants, and health and surveillance attendants ${ }^{6}$. Traditional birth attendants and "others" were regarded as unskilled HWs.

A woman who was checked by a skilled HW within 42 days of delivery was coded 1 and 0 otherwise. The study controlled for, among others, the area and region of residence, maternal age, maternal and paternal educational attainment and occupation, antenatal care (ANC), type and place of delivery, assistance during delivery, and gender, birth order, and birth weight of the child as these have been shown elsewhere to affect PNC uptake ${ }^{14-19}$.

\section{Results}

The summary statistics of the 6,693 women who responded to the question of whether or not they had a PNC after delivery of their child in the 24 months prior to the survey are in Table 1. The univariate analysis further showed that $48.4 \%$ of the 6,693 women were checked by a recommended skilled HW within 42 days of delivery.

Both adjusted and unadjusted logistic regressions models were fit in the study. Unadjusted logistic regression models were fit to observe whether some covariates had a significant effect on the utilization of PNC services, whereas the adjusted logistic regression model was fit to look at the impact of a covariate on PNC service uptake after controlling for potential confounders. The interpretation and discussion of the results was naturally based on the adjusted logistic regression model. The marital status variable was highly collinear with age of the partner, education attainment of the partner, and decision maker for the woman's health care, and was therefore dropped in the multivariate analysis. Table 2 presents some key results from these analyses. The full results have been included in the supplementary files.

Mothers who were working were 44\% [aOR: 1.44; 95\% CI: $1.22,1.70]$ more likely to be checked by a professional HW within 42 days of delivery than women who did not have a job. At household level, the odds of PNC uptake were $45 \%$ [aOR: 0.55; 95\% CI: 0.40, 0.76] less among women resident in rural areas than those in the urban areas.

Similarly, the odds of utilizing PNC were 46\% [aOR: 0.54; 95\% CI: $0.41,0.73$ ] less among women in the central region and 53\% [aOR: $0.47 ; 95 \%$ CI: $0.35,0.61]$ less among women in the southern region than the women in the northern region of Malawi. Mothers living in the richest wealth quintile were 28\% [aOR: $0.71 ; 95 \%$ CI: $0.53,0.98$ ] less likely to utilize PNC services unlike the women in the poorest wealth quintiles.

Women who had four or more ANC visits were 20\% [aOR: 1.20; 95\% CI: 1.02, 1.40] more likely to use PNC services than women who had the less than the number of WHO recommended ANC visits. Likewise, women whose pregnancy was protected by the adequate number of tetanus injections were 57\% [aOR: 1.57; 95\% CI: 1.21, 2.03] more likely to utilize PNC services than the women who did not receive the adequate number of tetanus injections. Delivery through caesarean section also increased the chances of PNC uptake by $93 \%$ [aOR: 1.89; 95\% CI: 1.38, 2.69]. Furthermore, the women who delivered in health facilities had a 91\% [aOR: 1.91; 95\% CI: 1.03, 3.55] higher probability of utilizing PNC services compared to women who delivered at home.

The analysis further showed that older women were more 
likely to utilize PNC services than younger women.

Table 1: Demographic and socio-economic distribution of the sample

\begin{tabular}{lcccc}
\hline Variable & \multicolumn{2}{c}{ Non Use ofPNC } & \multicolumn{2}{c}{ Use of PNC } \\
\cline { 2 - 5 } & Number & $\%$ & Number & $\%$ \\
\hline Age Of Mother & 545 & 15.80 & 413 & 12.74 \\
$<20$ & 1103 & 31.94 & 1,022 & 31.54 \\
$20-24$ & 738 & 21.38 & 715 & 22.08 \\
$25-29$ & 531 & 15.37 & 600 & 18.50 \\
$30-35$ & 535 & 15.51 & 491 & 15.14 \\
$36+$ & & & &
\end{tabular}

Maternal Educational

Attainment

None

Primary

Secondary And Higher

Health Care Decision

Respondent

Joint With Husband/

Partner

Husband/Partner/Other

$\begin{array}{llll}459 & 13.30 & 335 & 10.33\end{array}$

$2413 \quad 69.90 \quad 2,067 \quad 63.79$

$\begin{array}{llll}580 & 16.81 & 839 & 25.88\end{array}$

Residence

Urban

Rural

Child Wanted

Wanted Then

Wanted Later

Wanted No More

Gender

Male

Female

$\begin{array}{cccc}509 & 18.02 & 502 & 18.14 \\ 1292 & 45.77 & 1,373 & 49.62\end{array}$

$1022 \quad 36.21 \quad 892 \quad 32.24$

$\begin{array}{llll}349 & 10.12 & 562 & 17.35\end{array}$

$\begin{array}{llll}3104 & 89.88 & 2,678 & 82.65\end{array}$

\section{Birth Weight}

Low (<2,500 grams)

Normal Or High $(\geq 2,500$

grams)

\begin{tabular}{lcccc} 
Birth Order & 946 & 27.41 & 903 & 27.86 \\
First Births & 1653 & 47.89 & 1,610 & 49.67 \\
$2-4$ & 853 & 24.70 & 728 & 22.47 \\
$5+$ & & & & \\
\hline $\begin{array}{l}\text { Delivered Through } \\
\text { C-Section } \\
\text { No }\end{array}$ & 3303 & 96.27 & 2,923 & 90.20 \\
Yes & 128 & 3.73 & 318 & 9.80 \\
\hline
\end{tabular}

The odds of utilizing PNC services increased by $27 \%$ [aOR: 1.27; $95 \%$ CI: $0.94,1.70$ ] in the 20 to 24 age group; $35 \%$ [aOR: 1.35; 95\% CI: $0.99,1.91]$ in the 25 to 29 age group; $75 \%[a$ OR: $1.75 ; 95 \%$ CI: $1.22,2.51]$ in the 30 to 35 age group; and by $86 \%$ [aOR: 1.86; 95\% CI: 1.19, 2.92] among women aged 36 years and above, relative to women aged less than 20 years.

Table 2: Crude and adjusted odds ratios of use of postnatal care services among Malawian women

Variable Unadjusted Model (Crude) Adjusted Model

\begin{tabular}{|c|c|c|c|c|}
\hline & OR & $95 \% \mathrm{Cl}$ & OR & $95 \% \mathrm{Cl}$ \\
\hline \multicolumn{5}{|l|}{ Age Of Mother } \\
\hline$<20$ & 1 & & 1 & \\
\hline $20-24$ & 1.22 & {$[0.99,1.50]$} & 1.27 & {$[0.95,1.70]$} \\
\hline $25-29$ & $1.28^{*}$ & {$[1.02,1.61]$} & 1.35 & {$[0.99,1.91]$} \\
\hline $30-35$ & $1.49^{m+*}$ & {$[1.20,1.86]$} & $1.75^{* *}$ & {$[1.22,2.51]$} \\
\hline $36+$ & 1.21 & {$[0.96,1.54]$} & $1.86^{* \prime}$ & {$[1.19,2.92]$} \\
\hline \multicolumn{5}{|c|}{ Maternal Occupa- } \\
\hline tion Working & 1 & & & \\
\hline Working & $1.48^{*+*}$ & {$[1.29,1.70]$} & $1.44^{* *+}$ & {$[1.22,1.70]$} \\
\hline \multicolumn{5}{|l|}{ Residence } \\
\hline Urban & 1 & & 1 & \\
\hline Rural & $0.54^{* *+}$ & {$[0.43,0.67]$} & $0.55^{* \prime \prime}$ & {$[0.40,0.76]$} \\
\hline \multicolumn{5}{|l|}{ Region } \\
\hline Northern & 1 & & 1 & \\
\hline Central & $0.60^{* *+}$ & {$[0.47,0.76]$} & $0.54^{* * *}$ & {$[0.41,0.73]$} \\
\hline Southern & $0.45^{* *}$ & {$[0.36,0.57]$} & $0.47^{* *}$ & {$[0.35,0.61]$} \\
\hline \multicolumn{5}{|l|}{ Wealth Index } \\
\hline Poorest & 1 & & 1 & \\
\hline Poorer & $\begin{array}{l}1.00 \\
121^{*}\end{array}$ & {$[0.84,1.19]$} & $\begin{array}{l}0.86 \\
102\end{array}$ & {$[0.70,1.06]$} \\
\hline Richer & $1.42^{* *+}$ & {$[1.18,1.71]$} & $\begin{array}{l}1.02 \\
1.04\end{array}$ & {$[0.81,1.32]$} \\
\hline Richest & $1.77^{* *}$ & {$[1.42,2.22]$} & $0.72^{*}$ & {$[0.53,0.98]$} \\
\hline \multicolumn{5}{|l|}{ \# Of ANC Visits } \\
\hline$<4$ & 1 & & 1 & \\
\hline $4+$ & $1.49^{\prime *+}$ & {$[1.31,1.68]$} & $1.20^{*}$ & {$[1.02,1.40]$} \\
\hline \multicolumn{5}{|c|}{ Delivered Through } \\
\hline $\begin{array}{l}\text { C-Section } \\
\text { No }\end{array}$ & 1 & & 1 & \\
\hline Yes & $2.80^{* *+}$ & {$[2.01,3.72]$} & $1.93^{* * *}$ & {$[1.38,2.69]$} \\
\hline \multicolumn{5}{|l|}{ Place Of Birth } \\
\hline Home & 1 & & 1 & \\
\hline Health Facility & $5.36^{* *+}$ & {$[3.94,7.28]$} & $1.91^{*}$ & {$[1.03,3.55]$} \\
\hline \multicolumn{5}{|c|}{$\begin{array}{l}\text { Number Of Tetanus Injections } \\
\text { (Adequate) }\end{array}$} \\
\hline No & 1 & & 1 & \\
\hline Yes & $1.71^{m+*}$ & {$[1.39,2.12]$} & $1.57^{* *}$ & {$[1.21,2.03]$} \\
\hline $\begin{array}{l}\text { Number of Li } \\
\text { Children } \\
\leq 4\end{array}$ & 1 & & 1 & \\
\hline $5+$ & $0.80^{* \prime}$ & {$[0.69,0.93]$} & $0.03^{*}$ & {$[0.46,0.95]$} \\
\hline
\end{tabular}

It was further observed that education was not a significant factor in the utilization of PNC services. Women who had attained at least a primary education were 14\% [aOR: 0.86; 
95\% CI: 0.67, 1.11] less likely to use PNC services than women with no education at all.

On the other hand, the odds of using PNC services increased by $14 \%$ [aOR: $1.14 ; 95 \%$ CI: $0.82,1.57]$ among women who had attained secondary school or tertiary education than among women who had no education. Different patterns were observed in the effect of the respondents' partners on uptake of PNC services. A woman whose partner had obtained at least primary education was 16\% [aOR: 1.16; 95\% CI: $0.87,1.53$ more likely to access PNC services, whilst a woman whose partner had attained a secondary school qualification or tertiary education was 13\% [aOR: 1.13; 95\% CI: 0.82, 1.55] more likely to utilize PNC services than a woman whose husband had no education.

Although not statistically significant, the odds of accessing PNC services increased by 33\% [aOR: 1.33; 95\% CI: 0.99, 1.78] among women whose partners were working in comparison to women whose partners were not working. Women who were insured also had 92\% [aOR: 1.92; 95\% CI: 0.83, 4.45] more odds of using PNC services compared to women who were not covered by health insurance.

There was no notable difference [aOR: 0.98; 95\% CI: 0.78, $1.22]$ in the odds of utilizing PNC services among women who reported that getting permission to seek medical care at a hospital was not a constraint compared to women who reported that obtaining permission was a big problem. Likewise, no difference [aOR: 0.99; 95\% CI: $0.83,1.18$ ] in the chance of using PNC services was observed among women who reported that distance to a hospital was not a big problem compared to women who said the distance was a big problem.

Interestingly, women whose health care decision depended on them only were less likely to utilize PNC services compared to women whose health decision depended on their husband, partner or other relations. The odds of using PNC services increased by $8 \%$ [aOR: 1.08; 95\% CI: 0.87 , 1.35] among women whose health care decision depended on them and their partners; and also increased by $6 \%$ [aOR: 1.06; 95\% CI: 0.84, 1.34] among women whose health care decision depended on their partners or other people only, compared to women whose health care decision depended exclusively on themselves.

Uptake of PNC services did not significantly differ among women from different wealth quintiles. Women from poorer households were 14\% [aOR: 0.86; 95\% CI: 0.70, 1.06] less likely to utilize PNC services than women from poorest households. No difference in the uptake of PNC services was observed between women in the middle wealth quintile [aOR: 1.02; 95\% CI: 0.82, 1.28] and those in richer households [aOR: 1.04; 95\% CI: 0.81, 1.32] compared to women in the poorest households

Women who reported having wanted a child later than the time they had their pregnancy were 3\% [aOR: 0.97; 95\% CI: 0.82, 1.15] less likely to utilize PNC services compared to women who wanted a child at the time they had their pregnancy. Likewise, women who did not wish to have any more children had 10\% [aOR: 0.90; 95\% CI: 0.70, 1.15] less odds of utilizing PNC services than women who wanted the child. The women who had female children were also 3\% [aOR: 0.97; 95\% CI: 0.85, 1.12] less likely to use PNC services than the women who had male children.

Furthermore, uptake of PNC services did not statistically differ [aOR: 1.02; 95\% CI: 0.84, 1.24] between women who started attending ANC services in their first trimester and the women who started later. Women whose most current children were of the second to fourth order were 17\% [aOR: 0.83; 95\% CI: 0.66, 1.02] less likely to utilize PNC services compared to the women whose children were first born children. There was, also, no significant difference [aOR: 0.92; 95\% CI: 0.69, 1.40] in PNC uptake among women whose children were of the fifth or higher order birth were and the women whose children were of the first order of birth.

Furthermore, women whose birth was assisted by a skilled birth attendant were 8\% [aOR: 1.08; 95\% CI: 0.70, 1.66 ] more likely to use PNC services than women whose birth was not assisted by a skilled HW.

Women whose children were born with a weight of at least 2,500 grams were 21\% [aOR: 1.21; 95\% CI: 0.96, 1.54] more likely to attend PNC services than the women whose children were born with a low weight (less than 2,500 grams).

\section{Discussion}

PNC utilization in Malawi remains relatively low compared to WHO targets. For maternal and paternal characteristics, the analysis showed that women who were older were more likely to access PNC than younger ones. This is similar to what was reported in other studies ${ }^{15,20}$. Similarly, women with some form of education (whether primary or secondary) had higher odds of attending PNC than those with no education. These findings are consistent with what has been reported elsewhere ${ }^{17,20,21}$. This could be because women who are educated are literate and can efficiently process healthrelated information. Paternal education, likewise, increased the probability of a mother accessing ANC compared to lack of any formal education. A husband who is more educated would encourage health seeking behaviour in his wife. The odds of accessing PNC also increased for women who were working, and women whose partners were working. Somefun and Ibisomialso found that the probability of utilizing PNC services increased with increasing education status and wealth index of the mother ${ }^{22}$. Interventions should, therefore, also focus on women who are uneducated, and also those who come from poorer households. As recommended by Duysburgh and colleagues. ${ }^{8}$ after in-country consultations, Malawi could leverage community structures to educate women on the importance of utilizing PNC services. This approach would particularly be beneficial to uneducated women and also women in rural areas.

The results further suggest that women who were working and those that were insured were more likely to attend PNC than their counterparts. This result allies with the findings by Browne and colleagues. ${ }^{22}$, which showed that maternal health insurance tremendously increased the probability of a woman utilizing a range of services including PNC. Furthermore, other literature have discussed that women 
with paid employment have a higher chance of accessing services because of their economic independence ${ }^{18}$. This reinforces the need for promoting messages on importance of PNC utilization among women who are not well to do.

Women who did not consider the distance to a health facility or the permission to go to a health facility to be a barrier were more likely to utilize PNC services than women who did not. On the other hand, as expected, women whose health decision depended solely on other people including partners were less likely to utilize PNC services compared to women whose health decision depended on them only. On the contrary, women whose health decision depended on both her partner and herself were more likely to access PNC services than the women who made their own health decisions. These results suggest that joint decision-making in the household (or between spouses) can potentially increase utilization of PNC services. Other studies ${ }^{21,23}$ have suggested that utilization of PNC services increases with increasing decision making power of a woman. This highlights an important spillover effect of women empowerment initiatives.

Interesting patterns were also observed on parity and related indicators. Mothers who had a female child were less likely to utilize PNC services than the women who had given birth to a boy. Similarly, women who did not want any more children or did not want a child at that particular time had less odds of accessing PNC services than the women who wanted the child at the time they had their pregnancy.

Mothers with children of the second or higher birth order were less likely to attend PNC services compared to the women whose child was the first born. Furthermore, mothers who had five or more living children had less probability of accessing PNC services than women who had four or less living children. We hypothesize that the perceived importance of PNC decreases as the number of children a woman has increases. Surprisingly, mothers whose children had a normal or high birthweight had higher odds of utilizing PNC services unlike the mothers whose children were born with a low birth weight. It would be expected that mothers whose children were born with a low birth weight would be seeking PNC services because of the fragility of their babies ${ }^{16}$.

As expected, women who attended ANC four or more times had a higher probability of accessing PNC services than their counterparts. The women who received the WHO recommended number of tetanus injections also had a higher probability of attending PNC services than the women who did not have the recommended number. These results were also observed recently in South Sudan ${ }^{24}$. Tesfahun and Worku ${ }^{23}$ suggested that this could be a result of receiving adequate information on PNC services by the women who attended ANC frequently. In addition, women who made their first ANC visit in their first trimester were more likely to attend PNC services than those who had their first ANC visit late.

Higher odds of utilizing PNC services were observed from the women who delivered at a health facility than those who delivered at home or elsewhere. Similarly, a woman whose birth was assisted by a skilled HW was more likely to attend PNC services than a woman who was not assisted by a skilled HW. This could be because women who deliver at a health facility or are assisted by a skilled HW are advised to seek PNC services at the facility ${ }^{15}$. The results on the type of delivery were also in the expected direction. The women who delivered through a cesarean section had higher odds of utilizing PNC services relative to the women who had a normal birth. This result was also observed from Palestine where women who had a cesarean section had a high probability of utilizing PNC services than their counterparts ${ }^{25}$. Dhaher and colleagues ${ }^{25}$ argued this could be due to the perceived high risk among the women who did not have a spontaneous vaginal birth. Results from a study in Zomba, Malawi, ${ }^{10}$ also showed that women who did not have a caesarian were going back to the health facility to get their wound checked.

The chief strength of this study lies in the nationally representative data. One crucial limitation of the study was the inability to infer causal effects of the correlates on PNC utilization as cross-sectional data were used.

\section{Conclusion}

The study findings suggest that the utilization of postnatal care (PNC) services is generally higher among older women, the literate women, those who efficiently utilize antenatal care (ANC) services, and those who have a perceived high risk of a wound from their cesarean sections. Behavioural change interventions (BCIs) in Malawi should, therefore, target the poor women in Malawi who might otherwise not be able to access health promotion messages. Furthermore, BCIs should also focus on promoting messages that PNC services are critical to all women, regardless of whether or not they had a risky birth. Kumbani and colleagues ${ }^{12}$ suggested that the lack of utilization of PNC could also be attributed to the women's perception and their lack of knowledge of the quality of care to expect during their perinatal period (ANC, labour and delivery, management of complications during delivery, and PNC). We, therefore, also recommend that interventions focus on changing women's perception by giving comprehensive information on the importance of continued care throughout the perinatal period. Another study ${ }^{26}$ found that women who were accompanied by their husbands to ANC were more likely to access PNC than their counterparts. We, therefore, recommend advocating for male involvement in ANC and PNC.

\section{Additional files}

Table 3 presenting the socio-demographic distribution of the sample and Table 4 with the detailed results from the univariate and adjusted logistic regression models may be found online in the supporting information tab for this article.

\section{Authors' contributions}

Jessie Khaki, the first author, came up with the concept and originated the full drafts of the manuscript. Lonjezo Sithole meticulously reviewed the drafts and provided guidance on the technical approach as well as the language. Both authors worked closely on the analysis and interpretation of results. 


\section{Availability of data}

The data used in the study can be requested and downloaded from https://dhsprogram.com/data/.

\section{Competing interests}

The lead author is a Deputy Editor for the Malawi Medical Journal. However, the author was blinded from the review process of the manuscript.

\section{Funding}

The study was not funded by any organization.

\section{Acknowledgements}

We would like to thank the ICF Macro and Measure DHS for giving us permission to use the 2015-2016 MDHS dataset.

\section{References}

1. Warren C, Daly P, Toure L, Mongi P, Lawn J, Kerber K. Opportunities for Africa's newborns: Practical data, policy and programmatic support for newborn care in Africa. $1^{\text {st }}$ ed. Partnership for Maternal, Newborn and Child Health: Cape Town; 2008: p11-12.

2. World Health Organization. WHO technical consultation on postpartum and postnatal care [Internet]. 2010 [cited December 2017]. Available from: http://www.who.int/iris/handle/10665/70432

3. World Health Organization. WHO recommendations on postnatal care of the mother and newborn [Internet]. 2013 [cited January 2018]. Available from: https://www.who.int/maternal_child_adolescent/ documents/postnatal-care-recommendations/en/

4. World Health Organization. World Health Statistics 2016: Monitoring Health for the Sustainable Development Goals (SDGs) [Internet]. 2016 [cited January 2018]. Available from: World Health Organization. http://www.who.int/iris/handle/10665/206498

5. United Nations. Transforming our world: The 2030 agenda for sustainable development [Internet]. 2015 [cited January 2018]. Available from: https://sustainabledevelopment.un.org/post2015/ transformingourworld

6. National Statistical Office (NSO) [Malawi] and ICF. Malawi Demographic and Health Survey 2015-16. Zomba, Malawi, and Rockville, Maryland, USA. NSO and ICF. 2017

7. Kuruvilla S, Bustreo F, Kuo T, Mishra CK, Taylor K, Fogstad H et al. The Global strategy for women's, children's and adolescents' health (2016-2030): a roadmap based on evidence and country experience. Bull World Health Organ. 2016 1;94(5):398-400. doi: 10.2471/ BLT.16.170431

8. Duysburgh E, Kerstens B, Kouanda S, Kabore C, Yugbare B, Gichangi $\mathrm{P}$ et al. Opportunities to improve postpartum care for mothers and infants: design of context-specific packages of postpartum interventions in rural districts in four sub-Saharan African countries. BMC Pregnancy Childbirth. 2015; 15:131. doi:10.1186/s12884-015-0562-8.

9. The Malawi Government and Ministry of Health. National Sexual and Reproductive Health and Rights (SRHR) Policy (2017-2022).

10. Sakala B, Kazembe A. Factors influencing the utilisation of postnatal care at one week and six weeks among mothers at Zomba Central Hospital in Malawi. Evidence Based Midwifery. 2011: 9(4):113-136

11. Chimtembo LK, Maluwa A, Chimwaza A, Chirwa E, Pindani M. Assessment of quality of postnatal care services offered to mothers in Dedza district, Malawi. Open Journal of Nursing. 2013;03(04):343350. doi:10.4236/ojn.2013.34046.
12. Kumbani LC, Chirwa E, Malata A, Odland JØ, Bjune G. Do Malawian women critically assess the quality of care? A qualitative study on women's perceptions of perinatal care at a district hospital in Malawi. Reprod Health 2012;9:30. doi: 10.1186/1742-4755-9-30.

13. Machira H, Palamuleni M. Women's perspectives on quality of maternal health care services in Malawi. Int J Womens Health. 2018; 10: 25-34. doi: 10.2147/IJWH.S144426

14. Rwabufigiri BN, Mukamurigo J, Thomson DR, Hedt-Gautier BL, Semasaka JPS. Factors associated with postnatal care utilisation in Rwanda: A secondary analysis of 2010 Demographic and Health Survey data. BMC Pregnancy Childbirth. 2016;16:122. doi:10.1186/ s12884-016-0913-0.

15. Neupane S, Doku D. Utilization of postnatal care among Nepalese women. Matern Child Health J. 2013;17(10):1922-1930. doi:10.1007/ s10995-012-1218-1.

16. Somefun OD, Ibisomi L. Determinants of postnatal care nonutilization among women in Nigeria. BMC Res Notes. 2016;9:21. doi:10.1186/s13104-015-1823-3

17. Izudi J, Amongin D. Use of early postnatal care among postpartum women in Eastern Uganda. Int J of Gynecol Obstet. 2015;129(2):161164. doi:10.1016/j.ijgo.2014.11.017.

18. Khanal V, Adhikari M, Karkee R, Gavidia T. Factors associated with the utilisation of postnatal care services among the mothers of Nepal: Analysis of Nepal demographic and health survey 2011. BMC Women's Health. 2014;14:19. doi:10.1186/1472-6874-14-19.

19. Elkhoudri N, Baali A, Amor H. Postnatal care: Levels and determinants in Morocco. Iran J Public Health. 2017;46(2):242-248.

20. Pal R, Mehndiratta A. Assessment of utilization of postnatal care services in tertiary care center of Delhi. IOSR J Dental and Medical Sciences. 2016; 15(6).72-75. doi:10.9790/0853-1506017275.

21. Workineh YG, Hailu DA,. Factors Affecting Utilization of Postnatal Care Service in Amhara Region, Jabitena District, Ethiopia. Science Journal Public Health. 2014;2(3):169. doi:10.11648/j.sjph.20140203.15.

22. Browne JL, Kayode GA, Arhinful D, Fidder SAJ, Grobbee DE, Klipstein-Grobusch K. Health insurance determines antenatal, delivery and postnatal care utilisation: Evidence from the Ghana Demographic and Health Surveillance data. BMJ Open. 2016; 6:e008175doi:10.1136/ bmjopen-2015-008175.

23. Tesfahun F, Worku W, Mazengiya F, Kifle M. Knowledge, perception and utilization of postnatal care of mothers in Gondar Zuria District, Ethiopia: A Cross-sectional study. Matern Child Health J. 2014;18(10):2341-2351. doi:10.1007/s10995-014-1474-3.

24. Izudi J, Akwang GD, Amongin D. Early postnatal care use by postpartum mothers in Mundri East County, South Sudan. BMC Health Serv. Res. 2017; 17:442.doi:10.1186/s12913-017-2402-1.

25. Dhaher E, Mikolajczyk RT, Maxwell AE, Krämer A. Factors associated with lack of postnatal care among Palestinian women: A cross-sectional study of three clinics in the West Bank. BMC Pregnancy Childbirth. 2008;8. doi:10.1186/1471-2393-8-26.

26. Mullany B, Becker S, Hindin M. The Impact of Including Husbands in Antenatal Health Education Services on Maternal Health Practices in Urban Nepal: Results from a Randomized Controlled Trial. Health Educ. Res. 2007; 22(2):166-76. doi:10.1093/her/cyl060. 
Table 3: Demographic and socio-economic distribution of the sample

\begin{tabular}{|c|c|c|c|c|}
\hline \multirow[t]{2}{*}{ Variable } & \multicolumn{2}{|c|}{ Non Use of PNC } & \multicolumn{2}{|c|}{ Use of PNC } \\
\hline & Number & $\%$ & Number & $\%$ \\
\hline \multicolumn{5}{|l|}{ Age Of Mother } \\
\hline$<20$ & 545 & 15.80 & 413 & 12.74 \\
\hline $20-24$ & 1103 & 31.94 & 1,022 & 31.54 \\
\hline $25-29$ & 738 & 21.38 & 715 & 22.08 \\
\hline $30-35$ & 531 & 15.37 & 600 & 18.50 \\
\hline $36+$ & 535 & 15.51 & 491 & 15.14 \\
\hline \multicolumn{5}{|c|}{ Maternal Educational Attainment } \\
\hline None & 459 & 13.30 & 335 & 10.33 \\
\hline Primary & 2413 & 69.90 & 2,067 & 63.79 \\
\hline Secondary And Higher & 580 & 16.81 & 839 & 25.88 \\
\hline \multicolumn{5}{|c|}{ Paternal Educational Attainment } \\
\hline None & 346 & 12.26 & 223 & 8.06 \\
\hline Primary & 1582 & 56.04 & 1,436 & 51.90 \\
\hline Secondary And Higher & 895 & 31.70 & 1,108 & 40.04 \\
\hline \multicolumn{5}{|l|}{ Maternal Occupation } \\
\hline Not Working & 1412 & 40.90 & 1,033 & 31.87 \\
\hline Working & 2041 & 59.10 & 2,207 & 68.13 \\
\hline \multicolumn{5}{|l|}{ Paternal Occupation } \\
\hline Not Working & 316 & 11.21 & 198 & 7.17 \\
\hline Working & 2507 & 88.79 & 2,569 & 92.83 \\
\hline \multicolumn{5}{|l|}{ Insured } \\
\hline No & \multirow{2}{*}{3434} & 99.46 & \multirow{2}{*}{3,168} & 97.77 \\
\hline Yes & & 0.54 & & 2.23 \\
\hline \multicolumn{5}{|l|}{ Health Care Decision } \\
\hline Respondent & 509 & 18.02 & 502 & 18.14 \\
\hline Joint With Husband/Partner & 1292 & 45.77 & 1,373 & 49.62 \\
\hline Husband/Partner/Other & 1022 & 36.21 & 892 & 32.24 \\
\hline \multicolumn{5}{|c|}{ Permission To Go To The Hospital } \\
\hline A Big Problem & 617 & 17.87 & 520 & 16.05 \\
\hline Not A Big Problem & 2836 & 82.13 & 2,721 & 83.95 \\
\hline \multicolumn{5}{|l|}{ Distance To The Hospital } \\
\hline A Big Problem & 2027 & 58.70 & 1,803 & 55.65 \\
\hline Not A Big Problem & 1426 & 41.30 & 1,437 & 44.35 \\
\hline \multicolumn{5}{|l|}{ Residence } \\
\hline Urban & 349 & 10.12 & 562 & 17.35 \\
\hline Rural & 3104 & 89.88 & 2,678 & 82.65 \\
\hline \multicolumn{5}{|l|}{ Region } \\
\hline Northern & 286 & 8.28 & 482 & 14.87 \\
\hline Central & 1408 & 40.76 & 1,419 & 43.79 \\
\hline Southern & 1760 & 50.96 & 1,339 & 41.33 \\
\hline
\end{tabular}


Table 4: Demographic and socio-economic distribution of the sample (Continued)

\begin{tabular}{|c|c|c|c|c|}
\hline \multirow[t]{2}{*}{ Variable } & \multicolumn{2}{|c|}{ Non Use of PNC } & \multicolumn{2}{|c|}{ Use of PNC } \\
\hline & Number & $\%$ & Number & $\%$ \\
\hline \multicolumn{5}{|l|}{ Wealth Index } \\
\hline Poorest & 954 & 27.64 & 744 & 22.97 \\
\hline Poorer & 849 & 24.60 & 663 & 20.47 \\
\hline Poor & 669 & 19.36 & 626 & 19.33 \\
\hline Richer & 537 & 15.57 & 594 & 18.34 \\
\hline Richest & 443 & 12.83 & 612 & 18.90 \\
\hline \multicolumn{5}{|l|}{ Child Wanted } \\
\hline Wanted Then & 1865 & 54.01 & 1,879 & 58.00 \\
\hline Wanted Later & 1163 & 33.70 & 1,025 & 31.63 \\
\hline Wanted No More & 424 & 12.29 & 336 & 10.37 \\
\hline \multicolumn{5}{|l|}{ Gender } \\
\hline Male & 1730 & 50.12 & 1,661 & 51.27 \\
\hline Female & 1722 & 49.88 & 1,579 & 48.73 \\
\hline \multicolumn{5}{|l|}{ Birth Weight } \\
\hline Low (<2,500 grams) & 338 & 12.16 & 287 & 9.63 \\
\hline Normal Or High ( $\geq 2,500$ grams) & 2440 & 87.84 & 2,691 & 90.37 \\
\hline \multicolumn{5}{|l|}{ Birth Order } \\
\hline & 946 & 27.41 & 903 & 27.86 \\
\hline $2-4$ & 1653 & 47.89 & 1,610 & 49.67 \\
\hline $5+$ & 853 & 24.70 & 728 & 22.47 \\
\hline \multicolumn{5}{|l|}{ Timing Of First ANC Visit } \\
\hline First Trimester (Early) & 725 & 21.67 & 812 & 25.31 \\
\hline Late & 2621 & 78.33 & 2,398 & 74.69 \\
\hline \multicolumn{5}{|l|}{ Number Of ANC Visits } \\
\hline$<4$ & 1947 & 56.54 & 1,510 & 46.69 \\
\hline $4+$ & 1496 & 43.46 & 1,724 & 53.31 \\
\hline \multicolumn{5}{|l|}{ Delivered Through C-Section } \\
\hline No & 3303 & 96.27 & 2,923 & 90.20 \\
\hline Yes & 128 & 3.73 & 318 & 9.80 \\
\hline \multicolumn{5}{|l|}{ Place Of Birth } \\
\hline Home & 401 & 11.61 & 78 & 2.40 \\
\hline Health Facility & 3052 & 88.39 & 3,162 & 97.60 \\
\hline \multicolumn{5}{|l|}{ Skilled Attendant At Birth } \\
\hline No & 462 & 13.39 & 142 & 4.38 \\
\hline Yes & 2990 & 86.61 & 3,099 & 95.62 \\
\hline \multicolumn{5}{|c|}{ Number Of Tetanus Injections (Adequate) } \\
\hline No & 491 & 14.23 & 286 & 8.82 \\
\hline Yes & 2961 & 85.77 & 2,954 & 91.18 \\
\hline \multicolumn{5}{|l|}{ Parity } \\
\hline$\leq 4$ & 2739 & 79.34 & 2,680 & 82.69 \\
\hline $5+$ & 713 & 20.66 & 561 & 17.31 \\
\hline
\end{tabular}




\section{Table 4: Crude and adjusted odds ratios of use of postnatal care services among Malawian women}

\begin{tabular}{|c|c|c|c|c|}
\hline \multirow[t]{2}{*}{ Variable } & \multicolumn{2}{|c|}{ Unadjusted Model (Crude) } & \multicolumn{2}{|c|}{ Adjusted Model } \\
\hline & OR & $95 \% \mathrm{Cl}$ & OR & $95 \% \mathrm{Cl}$ \\
\hline \multicolumn{5}{|l|}{ Age Of Mother } \\
\hline$<20$ & 1 & & 1 & \\
\hline $20-24$ & 1.22 & {$[0.99,1.50]$} & 1.27 & {$[0.95,1.70]$} \\
\hline $25-29$ & $1.28^{*}$ & {$[1.02,1.61]$} & 1.35 & {$[0.99,1.91]$} \\
\hline $30-35$ & $1.49^{+* * *}$ & {$[1.20,1.86]$} & $1.75^{* *}$ & {$[1.22,2.51]$} \\
\hline $36+$ & 1.21 & {$[0.96,1.54]$} & $1.86^{* *}$ & {$[1.19,2.92]$} \\
\hline $\begin{array}{l}\text { Maternal Educational Attainment } \\
\text { None } \\
\text { Primary }\end{array}$ & $\begin{array}{l}1 \\
1.18\end{array}$ & {$[0.98,1.41]$} & $\begin{array}{l}1 \\
0.86\end{array}$ & {$[0.67,1.10]$} \\
\hline Secondary And Higher & $1.99^{*+* *+}$ & {$[1.57,2.51]$} & 1.14 & {$[0.82,1.57]$} \\
\hline \multicolumn{5}{|l|}{ Paternal Educational Attainment } \\
\hline None & 1 & & 1 & \\
\hline Primary & $1.41^{* *}$ & {$[1.11,1.79]$} & 1.55 & {$[0.87,1.53]$} \\
\hline Secondary And Higher & $1.92^{* * *}$ & {$[1.48,2.48]$} & 1.13 & {$[0.82,1.55]$} \\
\hline \multicolumn{5}{|l|}{ Maternal Occupation } \\
\hline $\begin{array}{l}\text { Not Working } \\
\text { Working }\end{array}$ & $\begin{array}{l}1 \\
1.48\end{array}$ & {$[1.29,1.70]$} & $\begin{array}{l}1.44^{* * *} \\
\end{array}$ & {$[1.22,1.70]$} \\
\hline \multicolumn{5}{|l|}{ Paternal Occupation } \\
\hline Not Working & 1 & & 1 & \\
\hline Working & $1.63^{*+* *}$ & {$[1.30,2.05]$} & 1.33 & {$[0.99,1.78]$} \\
\hline \multicolumn{5}{|l|}{ Insured } \\
\hline No & 1 & & 1 & \\
\hline Yes & $4.10^{* *}$ & {$[1.59,10.5]$} & 1.92 & {$[0.83,4.45]$} \\
\hline $\begin{array}{l}\text { Health Care Decision } \\
\text { Respondent }\end{array}$ & 1 & & 1 & \\
\hline Joint With Husband/Partner & 1.08 & {$[0.86,1.31]$} & 1.08 & {$[0.87,1.36]$} \\
\hline Husband/Partner /Other & 0.88 & {$[0.72,1.09]$} & 1.06 & {$[0.84,1.34]$} \\
\hline \multicolumn{5}{|l|}{ Permission To Go To The Hospital } \\
\hline A Big Problem & 1 & & 1 & \\
\hline Not A Big Problem & 1.14 & {$[0.95,1.36]$} & 0.98 & {$[0.78,1.22]$} \\
\hline \multicolumn{5}{|l|}{ Distance To The Hospital } \\
\hline A Big Problem & 1 & & 1 & \\
\hline Not A Big Problem & 1.13 & {$[0.98,1.31]$} & 0.99 & {$[0.83,1.18]$} \\
\hline \multicolumn{5}{|l|}{ Residence } \\
\hline Urban & 1 & & 1 & \\
\hline Rural & $0.54^{*+* *}$ & {$[0.43,0.67]$} & $0.55^{+* * *}$ & {$[0.40,0.76]$} \\
\hline \multicolumn{5}{|l|}{ Region } \\
\hline Northern & 1 & & 1 & \\
\hline Central & $0.60^{+* * *}$ & {$[0.47,0.76]$} & $0.54^{+* *+x}$ & {$[0.41,0.73]$} \\
\hline Southern & $0.45^{* * * *}$ & {$[0.36,0.57]$} & $0.47^{+* *+}$ & {$[0.35,0.61]$} \\
\hline
\end{tabular}


Table 4: Crude and adjusted odds ratios of use of postnatal care services among Malawian women (Continued)

\begin{tabular}{|c|c|c|c|c|}
\hline \multirow[t]{2}{*}{ Variable } & \multicolumn{2}{|c|}{ Unadjusted Model (Crude) } & \multicolumn{2}{|c|}{ Adjusted Model } \\
\hline & OR & $95 \% \mathrm{Cl}$ & OR & $95 \% \mathrm{Cl}$ \\
\hline \multicolumn{5}{|l|}{ Wealth Index } \\
\hline Poorest & 1 & & 1 & \\
\hline Poorer & 1.00 & {$[0.84,1.19]$} & 0.86 & {$[0.70,1.06]$} \\
\hline Poor & $1.21^{*}$ & {$[1.01,1.44]$} & 1.02 & {$[0.82,1.28]$} \\
\hline Richer & $1.42^{*+*}$ & {$[1.18,1.71]$} & 1.04 & {$[0.81,1.32]$} \\
\hline Richest & $1.77^{\text {t** }}$ & {$[1.42,2.22]$} & $0.72^{*}$ & {$[0.53,0.98]$} \\
\hline \multicolumn{5}{|l|}{ Child Wanted } \\
\hline & 1 & & 1 & \\
\hline Wanted Ihen & 0.87 & {$[0.76,1.00]$} & 0.97 & {$[0.82,1.15]$} \\
\hline Wanted Later & $0.79^{*}$ & {$[0.65,0.95]$} & 0.90 & {$[0.70,1.15]$} \\
\hline \multicolumn{5}{|l|}{$\frac{\text { Wanted No More }}{\text { Gender }}$} \\
\hline Male & 1 & & 1 & \\
\hline Female & 0.96 & {$[0.85,1.07]$} & 0.97 & {$[0.84,1.12]$} \\
\hline \multicolumn{5}{|l|}{ Birth Weight } \\
\hline Low (<2,500 grams) & 1 & & 1 & \\
\hline Normal Or High ( $\geq 2,500$ grams) & $1.30^{*}$ & {$[1.06,1.60]$} & 1.21 & {$[0.96,1.54]$} \\
\hline \multicolumn{5}{|l|}{ Birth Order } \\
\hline First Births & 1 & & 1 & \\
\hline $2-4$ & 1.02 & {$[0.89,1.17]$} & 0.83 & {$[0.66,1.02]$} \\
\hline $5+$ & 0.89 & {$[0.76,1.06]$} & 0.92 & {$[0.60,1.40]$} \\
\hline \multicolumn{5}{|l|}{ Timing Of First ANC Visit } \\
\hline First Trimester (Early) & 1 & & 1 & \\
\hline Late (4-9 Months) & $0.82^{*}$ & {$[0.70,0.96]$} & 1.02 & {$[0.84,1.24]$} \\
\hline \multicolumn{5}{|l|}{ \# Of ANC Visits } \\
\hline$<4$ & 1 & & 1 & \\
\hline $4+$ & $1.49^{* * *}$ & {$[1.31,1.68]$} & $1.20^{*}$ & {$[1.02,1.40]$} \\
\hline \multicolumn{5}{|l|}{ Delivered Through C-Section } \\
\hline No & 1 & & 1 & \\
\hline Yes & $2.80^{* *+*}$ & {$[2.01,3.72]$} & $1.93^{* *+*}$ & {$[1.38,2.69]$} \\
\hline \multicolumn{5}{|l|}{ Place Of Birth } \\
\hline Home & 1 & & 1 & \\
\hline Health Facility & $5.36^{* *+*}$ & {$[3.94,7.28]$} & $1.91^{*}$ & {$[1.03,3.55]$} \\
\hline \multicolumn{5}{|l|}{ Skilled Attendant At Birth } \\
\hline No & 1 & & 1 & \\
\hline Yes & $3.38^{* * *+}$ & {$[2.64,4.33]$} & 1.08 & {$[0.70,1.66]$} \\
\hline \multicolumn{5}{|c|}{ Number Of Tetanus Injections (Adequate) } \\
\hline No & 1 & & 1 & \\
\hline Yes & $1.71^{* *+*}$ & {$[1.39,2.12]$} & $1.57^{* *}$ & {$[1.21,2.03]$} \\
\hline $\begin{array}{l}\text { Number Of Living Children } \\
\leq 4\end{array}$ & 1 & & 1 & \\
\hline $5+$ & $0.80^{* *}$ & {$[0.69,0.93]$} & $0.03^{*}$ & {$[0.46,0.95]$} \\
\hline
\end{tabular}

